\title{
Sustainable Community Development Step 1: Get Stakeholder Agreement about Implementing a Sustainability Program ${ }^{1}$
}

M.E. Swisher, Sandra Rezola and James Sterns ${ }^{2}$

\section{Overview}

This document explains how to recruit and bring together stakeholders before implementing a sustainability program.

\section{Get Stakeholder Agreement about Implementing a Sustainability Program}

Florida's diversity in ethnic and racial groups and the population's differentiation by age, economic status, and educational achievement often make developing a sense of community difficult. Yet in order to strengthen community leadership and responsibility, these diverse individuals, with very different self-interests, must come together to plan, implement, and monitor sustainability programs, policies and projects. You may need to develop project specifics in collaboration with as many stakeholders as possible. Participative development allows community members to take a vested interest in working together to shape their collective future. Including all affected groups in the community promotes joint ownership of the process, increasing responsibility and accountability. In addition, solutions created through a multi-stakeholder process are likely to be more effective, increasing the probability of project success.

A multi-stakeholder process begins with the bringing together representatives with relevant interests from many different constituencies within the community. Consider individuals that may be positively or negatively affected by the project and those that can bring expertise or resources. Attempt to involve elected officials, neighborhood associations, environmental and other public interest groups, business representatives, religious organizations, government agencies, foundations, academic institutions, the media, and others. Additionally, an important component of any sustainability initiative is the recruitment and support of the community's youth. Your pursuit of new stakeholders should be ongoing, as time may reveal broader community linkages which may have not been as obvious at the start of your project. Early on, a planning group, composed of obvious, yet diverse stakeholders, may be helpful in identifying and recruiting additional stakeholders.

1. This document is FCS7214-Eng, one of a series of the Department of Family, Youth and Community Sciences, Florida Cooperative Extension Service, IFAS, University of Florida, Gainesville FL 32611: First published: September 2003. Reviewed by Jerry Culen, Ph.D., associate professor and Amy Simmone, Ph.D., assistant professor, Department of Family, Youth and Community Sciences, and Burl Long, Ph.D., professor, Department of Food and Resource Economics, University of Florida, Gainesville, Florida, 32611. Please visit the EDIS Web site at http://edis.ifas.ufl.edu

2. M.E. Swisher, Ph.D., associate professor, Department of Family, Youth and Community Sciences, Sandra Rezola, M.S., Institute of Food and Agricultural Sciences, and James Sterns, Ph.D., assistant professor, Department of Food and Resource Economics, University of Florida, Gainesville FL 32611. 
Be creative in your attempts to attract as many different stakeholders as possible. Often, this will entail utilizing multiple strategies to market the project, including the use of print and electronic media, public meetings and forums, using block or community leaders to spread the message, or going door-todoor to personally inform community members of the initiative. Be attentive to cultural or language differences that may limit your success in communicating your message and attracting diverse community members. It is important that you choose recruiters that are familiar with and sensitive to the culture, needs, and values of potential stakeholders.

Recruiting stakeholders involves convincing them of the benefit they will derive from becoming involved in a sustainability project and then giving them a meaningful way to contribute. Assess what would make that individual motivated to participate, be it personal or organizational, for this will largely determine an individual's extent of investment in the project.

Bringing together diverse stakeholders with varying needs, attitudes, beliefs and values, with the ultimate aim of agreeing on a common agenda toward sustainability, requires consensus building. Conflict is natural disagreement that, when properly channeled, can lead to useful and more long-lasting outcomes, creative problem-solving, and enhanced relationships.

While conflict may arise from different sources, getting from conflict to consensus often requires distinguishing positions from interests. Simply stated, a position is what you want and an interest is why you want it. For instance, one stakeholder may express her desire for using community funds to build a park while another may desire that the funds go toward increasing police presence within the community. Stated as such, this information is presented as conflicting positions. If interests were shared it might be revealed that stakeholder number one believes that a park can increase community interaction and provide the community's youth with healthy recreation, while stakeholder two would like to see increased police presence to deter the community's youth from crime and drug use. In this case, sharing interests revealed a common concern for which there may be a mutually satisfying solution. While understanding interests does not always guarantee a fair and equitable solution, interestbased negotiation helps reframe the issue in a way that increases the likelihood of reducing conflict and strengthening relationships.

In any consensus-building process it helps to establish ground rules for how the group will conduct itself. Among other things, ground rules should cover how and when the group will meet and how decisions will be made and agreed upon. Agreeing on the criteria you will use for solutions often entails identifying each person's "must have" bottom line. In addition, ground rules should cover what steps will be taken so that all participants are treated equitably and respected and allowed to participate fully. Rules on how responsibilities will be distributed and how newcomers will be integrated into the group are also helpful. It is often useful to have the ground rules written down and made visible during group meetings. 